\title{
Scenario analysis of balancing capacity market based on unit commitment
}

\author{
Nobuyuki Yamaguchi ${ }^{1, *}$, Nahoko Totsuka ${ }^{2}$, Koki Kakimoto ${ }^{2}$, Sekito Mizuno ${ }^{1}$, and Kogen Shibata ${ }^{1}$ \\ ${ }^{1}$ Tokyo University of Science, Graduate School of Engineering, 125-8585 Tokyo, Japan \\ ${ }^{2}$ Tokyo University of Science, Department of Engineering, 125-8585 Tokyo, Japan
}

\begin{abstract}
In 2021, it is scheduled for the creation of the balancing capacity market that can procurement and trade more flexible adjustment power than before, and the detailed design of the system is currently underway. As the number of providers of adjustment power increases as a result of marketization and broadening of the area, not only the reduction of procurement costs but also transparency and fairness of procurement are expected. In this paper, we propose the method to analysis scenarios of the balancing market based on Unit Commitment (UC) that considers the range of adjustment power secured in the regulation capacity market and quantitatively evaluate the effect of the adjustment power on the UC.
\end{abstract}

\section{Introduction}

In the electric energy sector, a large amount of renewable energy is expected to be introduced as one of the measures against global warming. Many researchers are working on the electricity market that is economically reasonable while maintaining reliability to introduce more photovoltaic (PV) and wind power generation with large output fluctuations to the power system [1-3]. In particular, the balancing capacity market to absorb the uncertain output of renewable energy power sources is extremely important [4-8]. In the Japanese electric power system reform, the creation of a supply and demand balancing market is planed in 2021. In this balancing market, flexible balancing power can be procured and traded more than before. At present, the detailed design of the system is currently underway. As the number of providers of balancing power increases due to the market creation and wide-area expansion, operators who have been able to provide only a part of functions until now can also provide adjustment power, thereby reducing procurement costs, transparency of procurement, Ensuring fairness is expected.

The broadening of the balancing capacity market discussed in Japan is to procure the balancing power of the local area from other areas of the interconnected system. The Japanese power system consists of nine control areas, and currently secures the supply capacity of its area from the power plants in each control area. In the future, if the supply and demand adjustment market appears and wide-area supply capability can be secured, the procurement cost and market price of adjustment capability can be expected to decrease. Flinkerbusch et al. has conducted a model analysis of a German interconnection system in one year since 2007 and found that the supply cost when coordinating power is procured over a wide area decreases [6]. Ortner et al. conducted a model analysis of the European grid in 2030 and argues that the impact of grid integration on the intra-day market is highly dependent on the region and technology [7]. Zalzar et al. also conducted a day-to-day market model analysis of the European grid in 2030, showing that the integration of the grid would benefit customers and reduce renewable energy output [8]. Newbery et al. explored combining interconnectors would improve the efficiency of trading day-ahead, intra-day and balancing services across borders [9]. Fattler et al. quantitatively evaluated the impact of "theoretical market coupling" and showed that EU Intraday-markets can significantly reduce the amount of flexibility [10].

The supply and demand balancing capability includes "procurement of balancing capacity" that secures the amount of power necessary to adjust the output capacity in advance and "operation of balancing power" that supplies the actual amount of power generated at the time of actual power supply. In the discussion on the balancing market in Japan, the procurement price of preserve power supply in advance is "delta-kW" price, and the operational price of actually generated power is trading as " $k W h$ " price.

In this study, we propose a method to examine the effect on Unit Commitment (UC) when the balancing power procured in the delta-kW balancing market is given as a scenario. Even if the power generation company supplies power via the delta-kW market, the spot market, and the intraday market, in this paper, it is assumed that the total fuel cost of each power plant is the fuel cost required for power generation as a whole society. The proposed method can quantitatively evaluate the effect of the amount of adjustment on UC, and the shadow price

Corresponding author: $\underline{\text { n-yama@rs.tus.ac.jp }}$ 
against supply costs, supply-demand balance, and balancing capability constraints. The numerical example shows a quantitative evaluation for the summer representative day of 2030 when a large amount of photovoltaic power generation will be introduced in nine control areas in Japan.

\section{Balancing Market and Capacity Requirement}

\subsection{Balancing Capacity Requirement}

Balancing power is the supply power for General Transmission and Distribution Companies to finally match supply and demand. Supply and demand must always match, but there will be a difference in the actual supply-demand balance. When demand is small compared to supply, power surplus occurs and the frequency rises. On the other hand, when demand increases, power becomes insufficient and the frequency drops. Since the frequency must always be kept constant, adjusting power is used to stabilize the system. There are demand forecasting errors, renewable energy forecasting errors, fluctuations in time, and power loss as events that can be dealt with by balancing power. Since renewable energy forecasting errors tend to increase in the daytime, the frequency is adjusted with generators that can be controlled online, such as increasing the number of generators simultaneously for each hour.

The electricity demand fluctuates in various cycles from the second to the hour in the day, and the fluctuation cannot be grasped in advance. For these various types of fluctuations, the supply and demand are matched by combining the balancing capabilities of different response speeds. In Japanese discussion, there are three types of balancing power: primary, secondary, and tertiary balancing power, which are distinguished by the response time and the duration of the operation. By performing control while transferring in the order of the primary, secondary, and tertiary balancing power, it is possible to operate while recovering from the next fluctuation. The primary balancing power may be fully operational within 10 seconds and sustain the operation for at least 5 minutes. The secondary balancing power is inherited from the primary balancing power and must maintain 30 minutes or more in response to a response within 5 minutes of fluctuations in supply and demand. Also, the tertiary balancing power must respond within 15 to 45 minutes and maintain up to 3 hours of operation. The ideal response of these adjustment powers is to control the frequency decrease by using the primary balancing power when, for example, an increase in demand is observed. After that, the frequency is restored to the reference frequency by utilizing the secondary adjustment power. With this delivery, the primary balancing power can be prepared for the next event. Lastly, the generator output of the tertiary balancing power is commanded, and economical changeover is implemented. Here, the transfer of the secondary balancing force to the tertiary balancing force is completed, and it can be recovered for the next event. It is expected that new operators will be able to

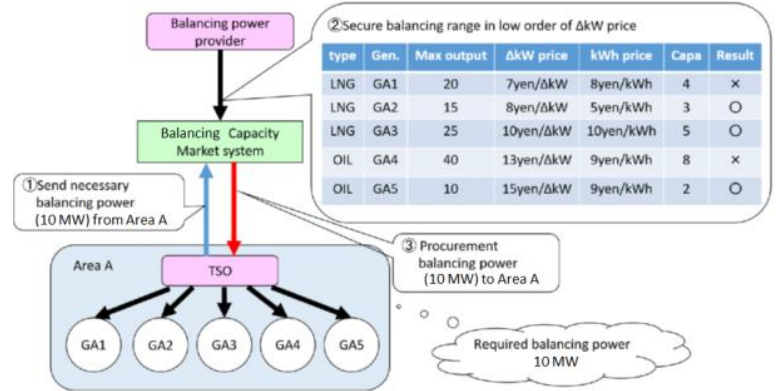

Fig. 1. Balancing capacity market

provide adjustment power by opening these markets by distinguishing these adjustment powers.

\subsection{Balancing Capacity Market called a Delta-kW market}

In the balancing capacity market, as in the current operation of balancing power, the amount of power necessary to balance the output at the time of actual supply and demand before gate close (GC) is secured for each product at each time. As mentioned above, there are two aspects: "procurement of balancing capacity" and "'operation of balancing power" that uses the balancing capacity secured before GC for errors actually generated after GC. The prices in these two aspects are set as the delta-kW prices and $\mathrm{kWh}$ prices in the balancing market mechanism, and the balancing power is procured and operated. Transactions are made with the procurement prices of secure power supply in advance as the delta-kW prices and the operational price of actually generated power as the $\mathrm{kWh}$ prices.

Fig. 1 shows the concept of the procurement of balancing power under consideration in the Japanese government. In the balancing market, the General Transmission and Distribution Company, who is the buyer, determines to secure $10 \mathrm{MW}$ balancing power requirements in Area A. Next, the balancing ability provider (seller) offers the target power source, the delta$\mathrm{kW}$ price at the time of activation, and the bid amount. Contracts are executed in ascending order of the delta-kW prices, and processing is performed until the secured balancing amount exceeds $10 \mathrm{MW}$, which is the required balancing power. After that, UC are executed to solve the generation schedule on the previous day when balancing power is actually secured with the contracted power supply, and procure to Area A.

\section{Method of scenario analysis of Delta- kW market based on UC}

\subsection{Steps for the Scenario Analysis}

The proposed analysis method follows the following three procedures.

\subsubsection{Step 1}


Table 1. Market participants position in delta $\mathrm{kW}$ market for each area on the representative day, August 5th.

\begin{tabular}{|c|c|c|c|c|c|c|c|c|c|c|c|}
\hline $\begin{array}{l}\text { Case } \\
\text { Num. }\end{array}$ & $\begin{array}{c}\text { Adjustment } \\
\text { Direction }\end{array}$ & $\begin{array}{l}\text { Fuel } \\
\text { Type }\end{array}$ & Area A & Area B & Area C & Area D & Area E & Area F & Area G & Area $\mathrm{H}$ & Area I \\
\hline \multirow{6}{*}{$\begin{array}{c}\text { Case } \\
1\end{array}$} & \multirow{3}{*}{ Upward } & Oil & 13.0 & 28.8 & 414.4 & 40.0 & 0.0 & 29.0 & 55.4 & 0.0 & 0.0 \\
\hline & & LNG & 341.4 & 862.2 & 2209.8 & 1649.0 & 255.0 & 1132.8 & 360.4 & 147.0 & 880.8 \\
\hline & & Coal & 0.0 & 0.0 & 0.0 & 0.0 & 0.0 & 0.0 & 480.2 & 260.2 & 607.4 \\
\hline & \multirow{3}{*}{ Downward } & Oil & 0.0 & 0.0 & 0.0 & 0.0 & 0.0 & 0.0 & 0.0 & 0.0 & 0.0 \\
\hline & & LNG & 366.4 & 862.2 & 2616.8 & 1649.0 & 255.0 & 1212.8 & 360.4 & 147.0 & 880.8 \\
\hline & & Coal & 0.0 & 0.0 & 0.0 & 0.0 & 0.0 & 0.0 & 480.2 & 260.2 & 607.4 \\
\hline \multirow{6}{*}{$\begin{array}{c}\text { Case } \\
2\end{array}$} & \multirow{3}{*}{ Upward } & Oil & 13.0 & 28.8 & 414.4 & 40.0 & 0.0 & 29.0 & 55.4 & 0.0 & 0.0 \\
\hline & & LNG & 25.0 & 643.2 & 3915.8 & 1768.0 & 0.0 & 1132.8 & 360.4 & 147.0 & 789.0 \\
\hline & & Coal & 0.0 & 0.0 & 0.0 & 0.0 & 0.0 & 0.0 & 0.0 & 0.0 & 0.0 \\
\hline & \multirow{3}{*}{ Downward } & Oil & 0.0 & 0.0 & 0.0 & 0.0 & 0.0 & 0.0 & 0.0 & 0.0 & 0.0 \\
\hline & & LNG & 25.5 & 643.2 & 4354.6 & 1768.0 & 0.0 & 1232.8 & 360.4 & 147.0 & 789.0 \\
\hline & & Coal & 0.0 & 0.0 & 0.0 & 0.0 & 0.0 & 0.0 & 0.0 & 0.0 & 0.0 \\
\hline
\end{tabular}

\section{* Unit: MW}

First, the amount of balancing power required for the power system is set. Future balancing capacity requirements are currently being discussed and are not exactly as stated previously. It will be determined in consideration of the effects of future renewable energy (solar and wind power generation) introduction and prediction errors. In the proposed method, the analyst gives the necessary amount of adjustment power.

\subsubsection{Step 2}

Next, we give a case for execution in the delta-kW market. In the Delta-kW market, it is unknown how much each power generator will bid for which power source. Therefore, the power supply to be executed is determined according to the case based on the analyst's assumption.

In this study, we will assume the case where power is supplied to the delta-kW market to satisfy the balancing power requirement for each region (case 1), and the case where the total adjustment power requirement for the whole country is supplied from the power supply nationwide (case 2).

In either case, the power generation company selects the power source for the Delta-kW market according to the following policy. As for the upward direction balancing capacity, oil-fired thermal power, LNG thermal power, and coal-fired thermal power with the highest fuel costs will be introduced into the market in this order. As for downward direction balancing capacity, LNG, which has the highest fuel cost, and coal-fired power will be put on the market in this order. However, since oil thermal power is unlikely to be contracted in the spot market, it is assumed that it has stopped on the day, so it is assumed that the down adjustment power cannot be sold to the Delta-kW market. This policy is based on the cost competitiveness of each power source in the spot market (energy market).

\subsubsection{Step 3}

Finally, UC is solved based on the set case, and the price due to changes in the type of contracted power supply and contracted number in the Delta-kW market is compared. $\mathrm{UC}$ here is the previous day's plan, and fluctuations in power supply and demand on that day are not covered.
This is because the prediction accuracy of power supply and demand for the day in the previous day plan is not a direct object of this study. However, the prediction accuracy in the previous day's plan can be considered to be included in the set value of the necessary amount of adjustment in the first procedure.

\subsection{Formulation of Unit Commitment}

The objective function represents a minimization program of fuel costs of thermal power plants and penalty factors regarding suppression of PV output, power shortage, and the usage of tie lines as follows:

$$
\begin{aligned}
& \text { Min } F=\sum_{\text {areai }} \sum_{t} \sum_{g}\left[C_{g, \text { areai }}^{s u} v_{t, \text { g,areai }}\right. \\
& +\left(C_{g, \text { areai }}^{\text {nl }}+a_{g, \text { areai }}^{f c}\right. \\
& \left.+C_{g, \text { areai }}^{\text {CO2fc }}\right) u_{t, \text { g,areai }} \\
& +\left(C_{g, \text { area }}^{g}+C_{g, \text { areai }}^{C O 2 f b}\right) p_{t, g, \text { areai }}^{g} \\
& +C^{s p t} p_{t, S P T, \text { areai }}+C^{s p r} p_{t, S P R, \text { areai }} \\
& +C^{s h} p_{t, S H, \text { areai }}+C^{\text {resUP }} p_{t, S H, \text { areai }}^{\text {resUP }} \\
& +C^{\text {resDOWN }} p_{t, S H, \text { areai }}^{\text {resDown }}+C^{\text {tie }} p_{t, \text { tie }}^{\text {planplus }} \\
& \left.+C^{\text {tie }} p_{t, t i e}^{\text {planminus }}\right]
\end{aligned}
$$

Where, $g$ and $i$ represent the indies of the thermal power plant and control area, respectively. A time interval is an hour in this study. The constants in Eqn. (1) are as follows: $C_{g, \text { areai }}^{\text {su }}$ : startup cost [JPY],

$C_{g, \text { areai }}^{n l}+a_{g, \text { areai }}^{f c}:$ no-load operation cost [JPY],

$C_{g, \text { area }_{i}}^{g}$ : coefficient of fuel cost [JPY/MW],

$C_{g, \text { areai }}^{\mathrm{CO} f b}, C_{\text {g,areai }}^{\mathrm{CO} f \mathrm{fc}}$ : penalty of carbon dioxide [JPY/MW],

$C^{s p t}$ : a penalty of a surplus generation not from renewable energy resources [JPY/MW],

$C^{s p r}$ : a penalty of a surplus generation from renewable energy resources [JPY/MW],

$C^{s h}$ : a penalty of power shortage [JPY/MW],

$C^{\text {resUP }}$ : a penalty of a shortage of upward regulation control capacity [JPY/MW],

$C^{\text {resDOWN }}$ : a penalty of a shortage of upward regulation control capacity [JPY/MW], 


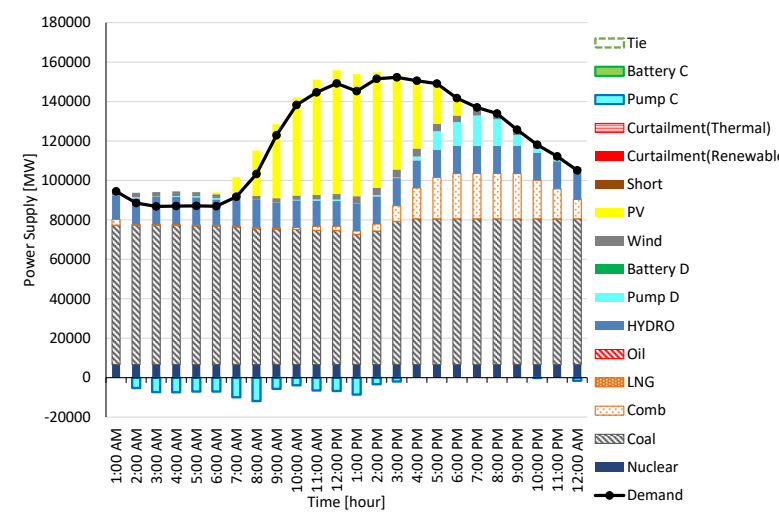

(a) Case 1

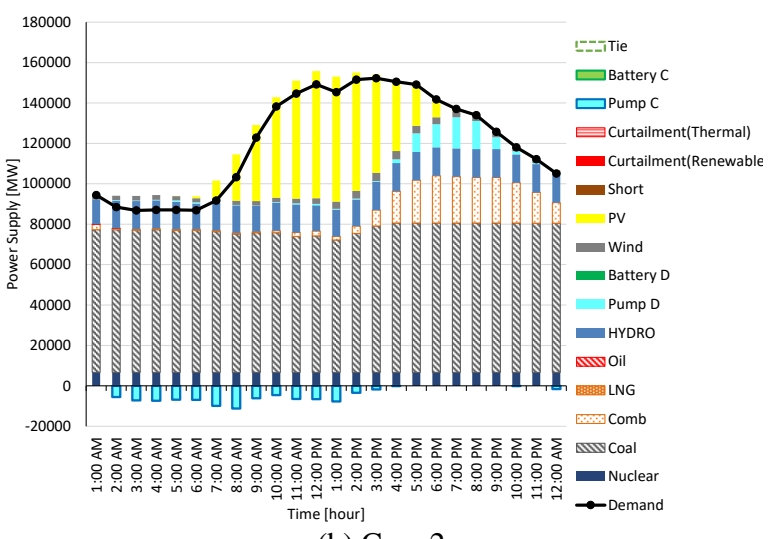

(b) Case 2

Fig. 2. Day-ahead operation schedule

$C^{\text {tie }}$ : a cost of usage of the interconnection tie lines [JPY/MW].

The variables should be solved as follows:

$p_{t, g, \text { areai }}^{g}$ : generating output from power plant $g[\mathrm{MW}]$,

$p_{t, S P T, a r e a i}:$ a surplus generation not from renewable energy resources [MW],

$p_{t, S P R, \text { areai }}$ : a surplus generation not from renewable energy resources [MW],

$p_{t, S H, \text { areai }}$ : power shortage [MW],

$u_{t, \text { g,areai }}, v_{t, g, \text { areai }}, l_{t, g, \text { areai }}$ : binary variables express operation status, startup status, and shutdown status, respectively,

$p_{t, S H, \text { areai }}^{\text {resUP }}, p_{t, S H, \text { areai }}^{\text {resDowN }}: \quad$ relax variables regarding upward/downward regulation control capacity [MW],

$p_{t, t i e}^{\text {planPlus }}$ : relax variables regarding forward tie-line flow [MW],

$p_{t, \text { tie }}^{\text {planMinus }}$ : relax variables regarding reverse tie-line flow [MW].

The constraints in this program represent the power balance of supply and demand, maximum and minimum generating output, the capacity requirement of upward and downward regulation control, the minimum uptime and downtime of the thermal power plants, the capacity of tie lines, and the capacity of pumped hydropower plants.

\section{Numerical experiments}

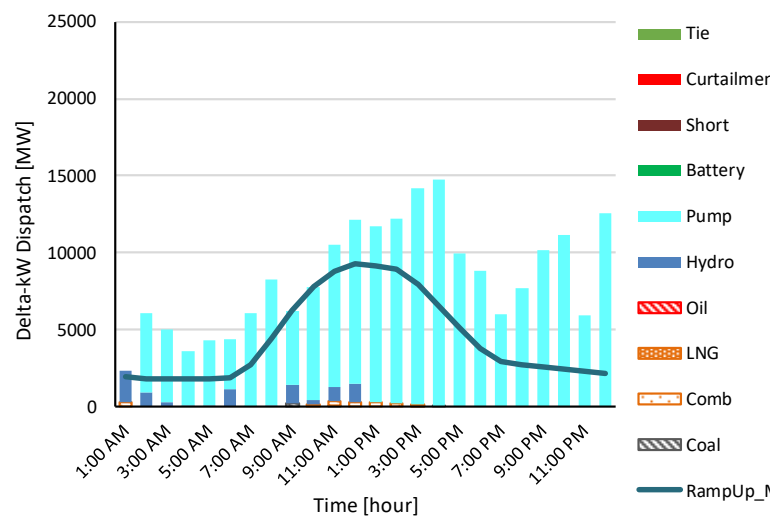

(a) Case 1

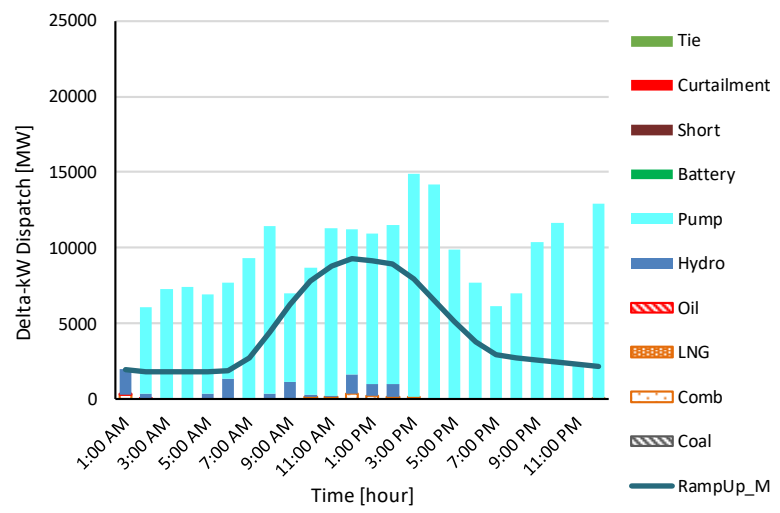

(b) Case 2

Fig. 3. Supply and demand of upward balancing power

\subsection{Assumptions}

In this study, August 5 is set as the representative day in 2030 , and scenario analysis is performed by changing the power supply contracted in the delta-kW market. As mentioned above, there are two scenarios:

Case 1: Procuring balancing power for each area,

Case 2: Procuring balancing power in the national pool.

The test system consists of 9 control areas and ten interconnection points which model the Japanese power system. In this system, there are 356 thermal power plants, 18 hydropower plants, 118 pumped hydropower plants for each control area. The output from nuclear power plants and renewable energy resources are subtracted from electricity demand in advance. Electricity demand in 2030 used in the experiment is assumed as the same in 2016.

The required amount of upward and downward balancing power is the product of PV output and PV prediction error rate, the product of wind power generation (WF) output and a prediction error rate of WF, and demand and instantaneous The sum of products with a reserve ratio of $2 \%$ is used.

The generators offered in the Delta-kW market are set to ensure $20 \%$ of the rated output as the balancing power. In the areas where the procured amount of balancing was less than the required amount, the remains of balancing power would be supplied from the hydropower and 


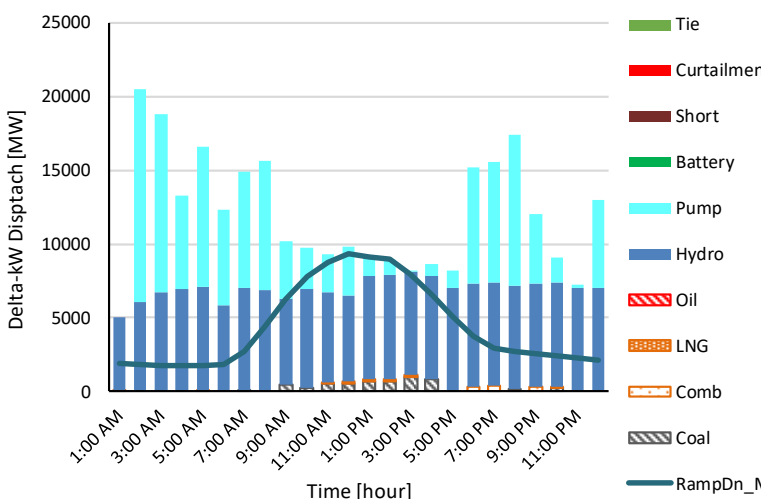

(a) Case 1

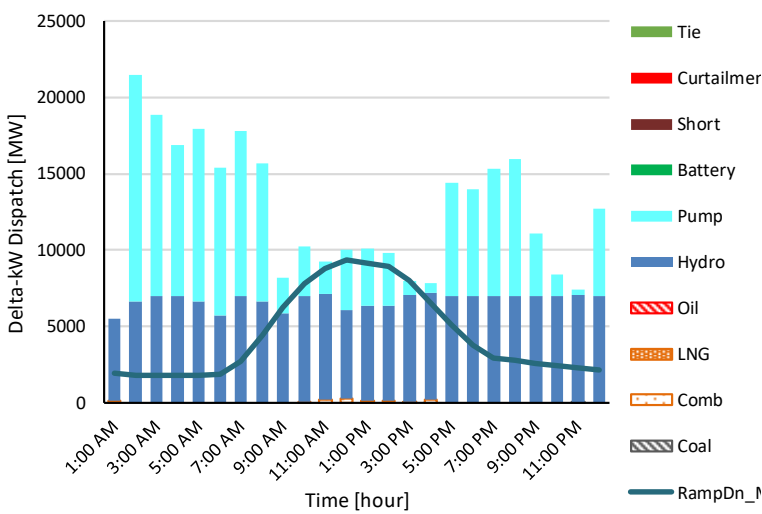

(b) Case 2

Fig. 4. Supply and demand of downward balancing power

pumped-storage power plants contracted by General Transmission and Distribution Companies.

\subsection{Results}

Fig. 1 shows the day-ahead operation schedules of case 1 and case 2 . These results mean that both schedules are almost the same. The pumped hydropower plants charge energy in the morning and discharge in the evening. On this representative day, PV contributes significantly to the load leveling.

Figs. 3 and 4 illustrate the dispatched upward and downward balancing power in the day-ahead schedules. Even though the balancing power is procured from some thermal power plants in the delta-kW market, the upward balancing power in Fig. 3 is almost shared by generation from pumped hydropower in cases 1 and 2 . The downward balancing power in Fig. 4 dispatchs from reservoir hydropower plants and pumped hydropower plants. Even in the case of downward balancing power, the thermal power plants were hardly operated.

Fig. 5 expresses the shadow prices regarding supply and demand energy balance. Because the market is separated into Area A (Hokkaido) and the remains, there are two series of shadow prices in each case. These shadow prices are almost the same in both cases.

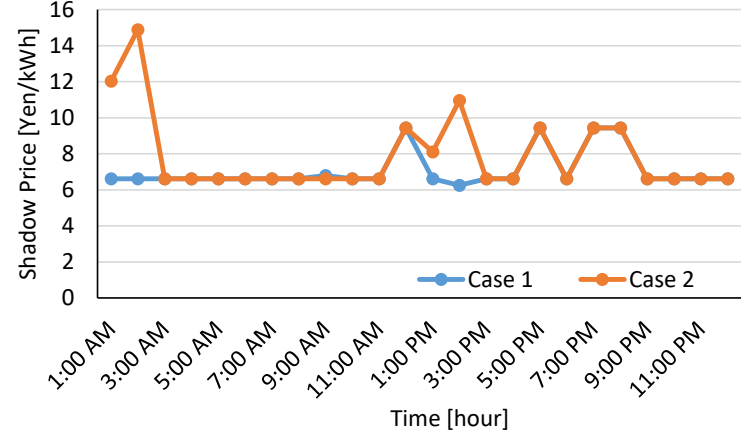

(a) Hokkaid area

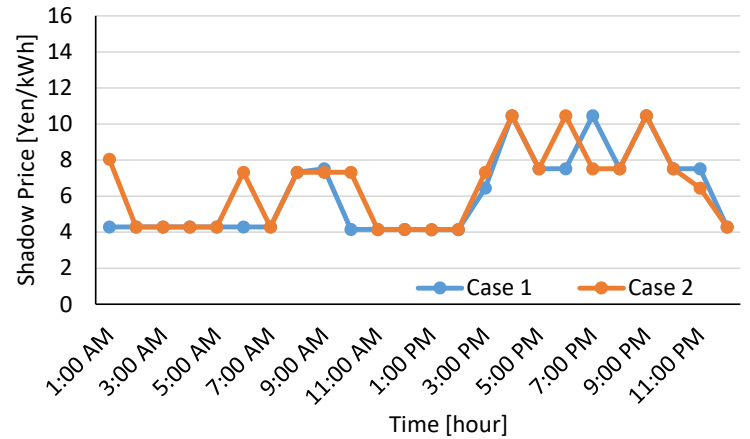

(b) The others

Fig. 5. Shadow prices regarding supply and demand energy balance

Figs. 6 and 7 describe the shadow prices of constraints of upward and downward balancing power in the dayahead operation schedules. The shadow prices are 0 JPY in not fewer regions and time zones. Since the day-ahead operation schedule almost satisfies simultaneously the balancing power constraints and the energy supply and demand constraint, the balancing power constraints not active. The shadow prices of case 1 in Fig. 6 are higher than the results of case 2 . In case 2, the number of areas in which have positive shadow prices is larger than the number in case 1 . These results depict that the nation-wide procurement of balancing power reliefs and is spread the burden of procurement of balancing power. Fig. 7 shows the same tendency with the comparison of cases 1 and 2 .

\section{Conclusion}

In this study, we proposed a method to evaluate the effect on the day-ahead operation schedule by assuming the balancing power market as a scenario. In the numerical examples on the representative day of summer, the shadow price in the balancing power was lower when the required balancing power is secured from the nation-wide procurement like Case 2.

In this study, when the amount secured in the Delta-kW market is not enough, the adjustment power by the hydro/pumped power plant is compensated, and the cost for this is not explicitly considered. In the future, we will conduct more detailed simulations of scenarios, such as 


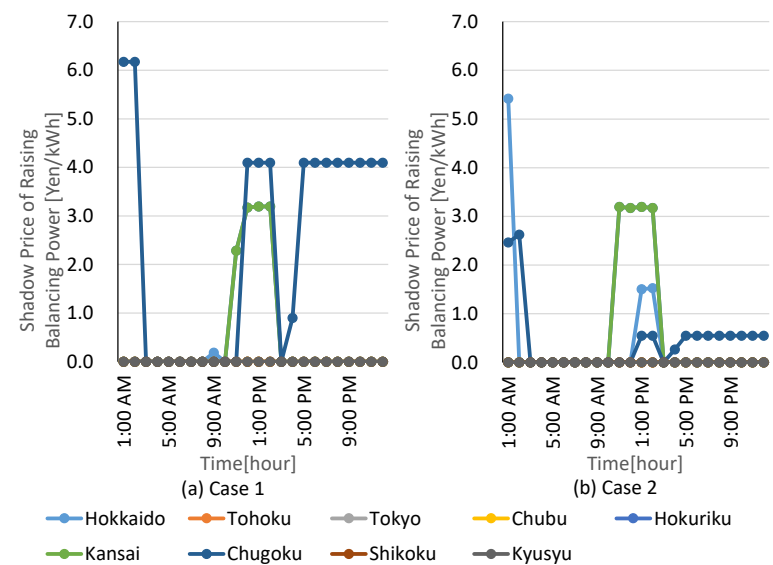

Fig. 6. Shadow prices regarding balancing power (upward)

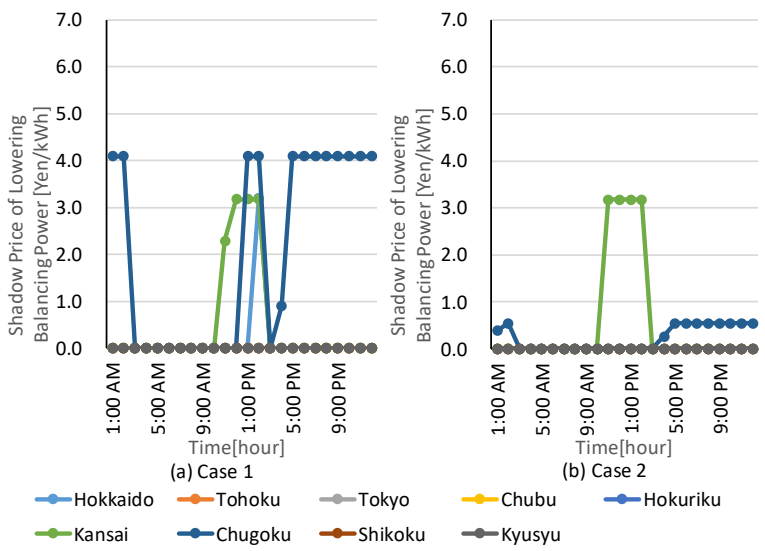

Fig. 7. Shadow prices regarding balancing power (downward)

penalizing for shortages and consider evaluation in terms of economy and procurement.

\section{References}

1. A. Bublitz, D. Keles, F. Zimmermann, C. Fraunholz, A survey on electricity market design: Insights from theory and real-world implementations of capacity remuneration mechanisms, Energy Economics 80, pp.1059-1078 (2019)

2. T. Levin, J. Kwon, A. Botterud, The long-term impacts of carbon and variable renewable energy policies on electricity market, Energy Policy 131, pp.53-71 (2019)

3. T. Gerres, J. Avila, F. Martinez, M. Abbad, R. Arin, A. Miralles, Rethinking the electricity market design: Remuneration mechanisms to reach high RES shares. Results from a Spanish case study, Energy Policy 129, pp.1320-1330 (2019)

4. R. Veen, R. Hakvoort, The electricity balancing market: Exploring the design challenge, Utilities Policy 43, pp.186-194 (2016)

5. J. Hu, R. Harmsen, W. Crijns-Graus, E. Worrell, M. Broek, Identifying barriers to large-scale integration of variable renewable electricity into the electricity market: a literature review of market design, Renewable and Sustainable Energy Reviews 81, pp.2181-2195 (2018)

6. K. Flinkerbusch, M. Heuterkes, Cost reduction potential in the German market for balancing power, Energy Policy 38, pp.4712-4718 (2010)

7. A. Ortner, G. Totschnig, The future relevance of electricity balancing markets in Europe-A 2030 case study, Energy Strategy Reviews 24, pp.111-120 (2019)

8. S. Zalzar, E. Bompard, A. Purvins, M. Masera, The impacts of an integrated European adjustment market for electricity under high share of renewables, Energy Policy 136 (2020)

9. D. Newbery, G. Strbac, I. Viehoff, The benefits of integrating European electricity markets, Energy Policy 94 , pp.253-263 (2016)

10. S. Fattler, C. Pellinger, The value of flexibility and the effect of an integrated European Intraday-Market, IEEE International Conference on the European Energy Market (EEM) (2016) 